\title{
Reproductive fitness of Meloidogyne artiellia populations on chickpea and durum wheat
}

\author{
Víctor Hernández FernándeZ ${ }^{1}$, Jorge MARTín BARbARRojA ${ }^{1}$, Rafael M. JimÉnez Díaz ${ }^{1,2}$ \\ and Pablo CASTILlo ${ }^{1, *}$ \\ ${ }^{1}$ Instituto de Agricultura Sostenible, Consejo Superior de Investigaciones Científicas (CSIC), Apdo. 4084, \\ 14080-Córdoba, Spain \\ ${ }^{2}$ Escuela Técnica Superior de Ingenieros Agrónomos y de Montes (ETSIAM), Apdo. 3048, 14080-Córdoba, Spain
}

Received: 5 July 2004; revised: 20 January 2005

Accepted for publication: 24 January 2005

\begin{abstract}
Summary - The influence of chickpea and durum wheat, as crops widely used in rotations in the Mediterranean Basin, on the reproductive fitness of five Meloidogyne artiellia populations from Italy, Spain and Syria, was investigated under controlled conditions. The reproductive fitness of the $M$. artiellia populations, determined as the number of eggs per mature egg mass, was significantly greater in durum wheat cv. Simeto than in chickpea cv. UC 27 for all five nematode populations. Similarly, both in chickpea and durum wheat the reproductive fitness differed among nematode populations, with populations of $M$. artiellia from Castel del Monte (southern Italy) and CL5 (northern Spain) producing the greatest number of eggs per egg mass. The fewest number of eggs per egg mass of $M$. artiellia occurred for populations from Alhama 6 (southern Spain) and Tel-Hadya (northern Syria).
\end{abstract}

Keywords - eggs, egg masses, geographic origin, Mediterranean Basin, reproduction.

Meloidogyne artiellia Franklin is an important rootknot nematode in the Mediterranean Basin, especially on leguminous crops such as chickpea (Cicer arietinum L.) (Greco, 1984) and cereals such as durum wheat (Triticum durum Desf.), which are widely used in crop rotations in this area (Kyrou, 1969; Ritter, 1972; Tobar Jiménez, 1973; Di Vito \& Zaccheo, 1987). Attacks by M. artiellia caused severe losses of chickpea seed yield in several countries of the Mediterranean Basin, where 10-12\% of stunted chickpeas were infected with the nematode (Tobar Jiménez, 1973; Greco, 1984; Di Vito \& Greco, 1988). Additionally, infections of chickpea by M. artiellia can break down valuable complete and partial resistance against highly virulent Fusarium oxysporum f. sp. ciceris race 5 when coinfections of a plant with the two pathogens occur (Castillo et al., 2003).

The reproductive fitness of a pathogen while growing in a host plant (aggressiveness or parasitic fitness) together with virulence are major components of pathogenicity (Shaner et al., 1992) and, thus, are important for the assessment and understanding of disease reactions of plants to pathogens. Most research on Meloidogyne aggressive- ness has been conducted by measuring the nematode reproduction within the host, such as eggs produced per $\mathrm{g}$ of root (Van der Beek et al., 1997; Tzortzakakis et al., 1998). Similarly, reproduction variability is important for designing strategies for management of plant-parasitic nematodes, particularly for breeding and selecting resistant lines to root-knot nematodes.

Therefore, this present study was undertaken to determine the influence of the host plant (chickpea and durum wheat) and diversity of $M$. artiellia populations on the nematode reproductive fitness determined as the number of eggs per mature egg mass.

\section{Materials and methods}

\section{NeMATOdE INOCULUM}

Nematode populations used in this study were obtained from roots of chickpea and durum wheat collected in commercial fields of Italy, Spain and Syria (Table 1). Ten infected plants were arbitrarily chosen from each of the sampled fields and an egg mass from a single female

*Corresponding author, e-mail: ag1cascp@uco.es 
Table 1. Populations of Meloidogyne artiellia used in the study* .

\begin{tabular}{|c|c|c|}
\hline $\begin{array}{l}\text { M. artiellia } \\
\text { population }\end{array}$ & Host & Locality \\
\hline Alhama 6 & Chickpea & $\begin{array}{l}\text { Alhama de Granada (Granada } \\
\text { province), southern Spain }\end{array}$ \\
\hline Castel del Monte & Chickpea & $\begin{array}{l}\text { Castel del Monte (Bari province), } \\
\text { southern Italy }\end{array}$ \\
\hline CL5 & Chickpea & $\begin{array}{l}\text { Fuentesauco (Zamora province), } \\
\text { northern Spain }\end{array}$ \\
\hline Gravina & $\begin{array}{l}\text { Durum } \\
\text { wheat }\end{array}$ & $\begin{array}{l}\text { Gravina in Puglia (Bari province), } \\
\text { southern Italy }\end{array}$ \\
\hline Tel-Hadya & Chickpea & Tel-Hadya, northern Syria \\
\hline
\end{tabular}

\footnotetext{
* Nematodes were isolated from infected roots of the given crop plant.
}

in each of the plants was selected. To establish and increase inoculum of $M$. artiellia for experiments, the individual egg masses removed from the host roots were surface-disinfested in $1 \% \mathrm{NaOCl}$ for 4 min, rinsed thoroughly in sterilised water and placed onto roots of a 23-week-old 'UC 27' chickpea plant. Plants were grown in an autoclaved $\left(121^{\circ} \mathrm{C}\right.$ for $1 \mathrm{~h}$, twice on 2 consecutive days) soil mixture (sand : clay loam, 2:1, v/v) at $21 \pm 1^{\circ} \mathrm{C}$ with a $14 \mathrm{~h}$ photoperiod of fluorescent light at $360 \pm 25 \mu \mathrm{Em}^{-2} \mathrm{~s}^{-1}$. Inoculated plants were incubated for 2-3 months. Ten infected plants (representing ten initial egg masses per nematode population) were raised using this procedure to increase the nematode inoculum to the amount required for experiments.

\section{REPRODUCTIVE FITNESS ASSAYS}

To assess the reproductive fitness of $M$. artiellia populations in chickpea and durum wheat, about 100 mature (at least 70-day-old), uniformly sized, egg masses of each nematode population were selected for the study. Nematodeinfected roots of 'UC 27' chickpeas were collected from the stock culture and washed thoroughly with running tap water. Egg masses were hand picked in a laminar flow of filtered air, surface-disinfested as above, and all subsequent procedures were completed under sterile conditions. Egg masses of each population were placed in hatch chambers comprising $20 \mathrm{~mm}$ diam. micro sieves $(75 \mu \mathrm{m}$ aperture) enclosed in Petri dishes. Petri dishes were filled with sterile, deionised distilled water to cover the egg masses (Pérez et al., 2003). Petri dishes were placed in the dark in an incubator adjusted at $20 \pm 1^{\circ} \mathrm{C}$ for $96 \mathrm{~h}$, and the emerging second-stage juveniles (J2) were collected.
Chickpea cv. UC 27 and durum wheat cv. Simeto seeds were surface-disinfested in $2 \% \mathrm{NaOCl}$ for 3 min and germinated on sterile, moistened filter paper in Petri dishes at $25^{\circ} \mathrm{C}$ in the dark for $48-72 \mathrm{~h}$. Four germinated seeds, selected for uniformity (length of radicle $=1-2 \mathrm{~cm}$ ), were sown into $15 \mathrm{~cm}$ diam. clay pots (one seed per pot) filled with 0.51 of the autoclaved soil mixture. For inoculation, nematode concentrations were determined in $1 \mathrm{ml}$ aliquots of water suspension. To assure a homogeneous developmental status in the plant-parasite interaction for the five M. artiellia populations studied, plants were inoculated with 1000 just-emerged $\mathrm{J} 2$ in $10 \mathrm{ml}$ of sterile distilled water around a root radicle at sowing. To make sure that infections were contemporary, 4 days after inoculation seedlings were removed from soil in a pot and the roots of each seedling were washed thoroughly and transplanted into nematode-free soil mixture. Thereafter, plants were incubated in a growth chamber adjusted to the same conditions mentioned above for 60 days. Plants in pots were watered as needed and fertilised with $100 \mathrm{ml}$ of a $0.1 \%$, 20-5-32+micronutrients hydro-sol fertiliser (Haifa Chemicals Ltd, Haifa, Israel) solution every week. The experiment consisted of a factorial treatment design comprising two host plants and five nematode populations. There were four replications in a randomised complete block design.

At the end of the experiment, the roots of each plant were washed free of soil. To assess the reproductive fitness of each M. artiellia population, 25 mature egg masses of each nematode were selected at random from each plant and hand picked from infected roots to achieve 100 egg masses per treatment combination. A single egg mass was deposited within a $10 \mathrm{ml}$ glass tube. The number of eggs per egg mass was determined after exposure to $1 \%$ $\mathrm{NaOCl}$ for 4 min (Hussey \& Barker, 1973) and vortexed for $5 \mathrm{~min}$. Then, egg suspensions were transferred to a counting Peter's slide and eggs were counted under the stereomicroscope.

\section{STATISTICAL ANALYSiS}

The experiment was repeated once and similarity between experiments was tested by preliminary analyses of variance using experimental runs as blocks. Data of egg numbers per egg mass were normalised before analysis by transforming them into $\log _{10}(X+1)$ (Gomez \& Gomez, 1984). Analyses of variance were carried out using Statistix 8.0 (NH Analytical Software, Roseville, MN, USA). Mean egg numbers per egg mass were compared using 
Table 2. Numbers of eggs per egg mass produced by five populations of Meloidogyne artiellia on durum wheat and chickpea (data are means of two experiments, with 100 replicates of each plant-nematode combination per experiment $)^{\mathrm{a}}$.

\begin{tabular}{lccccrrr}
\hline M. artiellia population & \multicolumn{3}{c}{ Wheat } & & \multicolumn{3}{c}{ Chickpea } \\
\cline { 2 - 3 } & Mean & SE & Range & & Mean & SE $^{\mathrm{b}}$ & Range $^{\mathrm{b}}$ \\
\hline Castel del Monte & $275.09 \mathrm{aA}$ & 6.77 & $114-596$ & & $230.46 \mathrm{aB}$ & 3.50 & $148-358$ \\
CL5 & $271.92 \mathrm{aA}$ & 5.10 & $118-498$ & & $229.74 \mathrm{abB}$ & 4.35 & $110-397$ \\
Gravina & $248.48 \mathrm{bA}$ & 5.40 & $132-511$ & & $227.41 \mathrm{aB}$ & 2.61 & $157-309$ \\
Alhama 6 & $230.60 \mathrm{cA}$ & 3.40 & $137-371$ & & $218.94 \mathrm{bB}$ & 3.62 & $142-362$ \\
Tel-Hadya & $232.95 \mathrm{bcA}$ & 3.52 & $144-430$ & & $205.68 \mathrm{cB}$ & 2.65 & $129-301$ \\
MEAN & $251.81 \mathrm{~A}$ & & $114-596$ & & $222.44 \mathrm{~B}$ & & $110-397$ \\
\hline
\end{tabular}

${ }^{a}$ Means followed by common lower case letters in a column and by common upper case letter in a row are not significantly different $(P>0.05)$ according to Fisher's protected LSD test. Analyses were carried out using $\log _{10}(X+1)$ transformed data, untransformed means are tabulated.

${ }^{\mathrm{b}}$ Standard error of the means.

Fisher's protected least significant difference test (LSD) at $P=0.05$.

\section{Results}

The two experiments did not differ according to analysis of variance for experiment effect $(F=0.68, P=$ 0.4082 ). This allowed combining data for analysis of variance. In the two experimental runs, all five M. artiellia populations infected and reproduced on chickpea cv. UC 27 and durum wheat cv. Simeto (Table 2). The reproductive fitness, determined by the number of eggs per egg mass, was significantly influenced by the host plant $(F=$ $100.8, P<0.0001)$, nematode population $(F=19.44$, $P<0.0001)$, as well as the host plant $\times$ nematode population interaction $(F=4.12, P=0.0025)$. Due to the significant interaction host plant $\times$ nematode population, the ANOVA analysis was performed by host plant across $M$. artiellia populations and by $M$. artiellia populations across host plants, separately (Table 2). In these analyses, the reproductive fitness of $M$. artiellia populations was significantly greater in durum wheat (cv. Simeto) than that in 'UC 27' chickpea for all five nematode populations (Table 2). In durum wheat, the reproductive fitness was significantly higher in populations of $M$. artiellia from Castel del Monte (southern Italy) and CL5 (northern Spain), with the fewest number of eggs per egg mass occurring in population of M. artiellia from Alhama 6 (southern Spain) (Table 2). In chickpea, lower significant differences were detected in the number of eggs per egg mass compared with that in durum wheat, with the population of $M$. artiel- lia from Tel-Hadya (northern Syria) showing the lowest reproduction fitness (Table 2).

\section{Discussion}

Although the growing seasons of durum wheat and chickpea in the Mediterranean Basin are about 8 and 4 months, respectively, under the controlled conditions used in these experiments roots of both host plants are active up to 65-70 days of incubation. However, in both host plants, longer time periods of incubation under the controlled conditions used in our experiments would show plant senescence symptoms (Castillo et al., 1998). Consequently, the availability of fresh root tissues for nematode feeding would be threatened. In addition, as established by Di Vito and Greco (1988), $10^{\circ} \mathrm{C}$ is the basal threshold temperature for the development of M. artiellia and, thus, the nematode usually completes one generation during the growing season in Mediterranean environments. No systematic studies on the relationships between the cumulative number of eggs produced per female and elapsed degree days from first egg production in $M$. artiellia have been developed. However, similar studies on M. arenaria in grape varieties, also with a basal threshold temperature of $10^{\circ} \mathrm{C}\left(\mathrm{DD}_{10}\right)$, showed a continuous increase in egg production per female up to $550 \mathrm{DD}_{10}$, and remained constant from 550-700 $\mathrm{DD}_{10}$ (Ferris et al., 1984). In our study to evaluate the number of eggs per egg mass produced by M. artiellia populations, we selected a time period of 64 days of incubation that is equivalent to $960 \mathrm{DD}_{10}$ and assures the maximum production of eggs per female at optimal conditions. Therefore, some possible differences 
in the relationship temperature/development among the $M$. artiellia populations in our study are covered by the wide range of time of incubation used. Additionally, although no systematic evaluation of the primary infections with $\mathrm{J} 2$ or the number of egg-laying females per root system were carried out, the number of egg-laying females was around 50-80 per root system of durum wheat or chickpea and, therefore, must be considered low enough to avoid competition between them.

Understanding the interaction between host genotypes and populations of nematode species is of importance for the management of plant-parasitic nematodes and has been a subject of concern in the research of plant nematologists. The primary objective of this study was to determine the influence of chickpea and durum wheat as hosts of $M$. artiellia and the reproductive fitness of populations of diverse origin of the nematode.

Our results indicate that durum wheat cv. Simeto is a better host of this nematode compared with chickpea cv. UC 27. Those findings agree with previous studies (Di Vito \& Zaccheo, 1987; Di Vito \& Greco, 1988) and confirm the influence of the host plant on the production of eggs per egg mass in $M$. artiellia. The quantitative differences in nematode reproduction found in our study can be attributed to differences in genes regulating the host-parasite interaction (Anwar et al., 2000), since the two nematode populations from nearby locations in Italy (Castel del Monte and Gravina) differ significantly in their reproductive capacity on durum wheat. Ferris et al. (1984) reported a similar finding in a study of the reproductive fitness of $M$. arenaria. These authors hypothesised that once a successful nematode infection site is established, a constant number of eggs per egg mass is produced if favourable environmental conditions prevail.

The egg content of the egg masses in M. artiellia has not been studied in a large number of egg masses prior to the present work. Nevertheless, Di Vito and Greco (1988) reported that a population of $M$. artiellia from Monopoli, southern Italy, produced up to 600 eggs per egg mass in chickpea cv. Ghab 1 in microplot experiments, which is much higher compared with the reproduction of the nematode populations on chickpea in this study. Differences in the environmental and experimental conditions, aggressiveness of the $M$. artiellia populations, or differences in the genotype of tested plant material could account for the differences between the two studies.

Apart from M. artiellia, other studies suggested that variations in the reproductive fitness (as indicated by the ability to produce eggs per egg mass on a host root) do occur among field populations of Meloidogyne spp. (Petrillo \& Roberts, 1997; Van der Beek et al., 1997), which indicates that those populations may differ in the genetic factors controlling reproductive fitness in each population. Similarly, the characteristic features in the biology and development of different Meloidogyne spp. may also play a role in those differences. In addition, although different $M$. artiellia populations showed variation in reproductive fitness under controlled environmental conditions in this study, such variation would not necessarily be exhibited under field conditions - this warrants further investigation.

In summary, in this study we have addressed the question of whether or not the egg-laying potential of $M$. artiellia is significantly influenced by the host genotype and the geographic origin of the nematode populations. We conclude that both the plant and nematode genotypes have a significant influence on the capacity of individual females to produce a given number of eggs, and that $M$. artiellia populations show differential reproductive fitness.

\section{Acknowledgements}

Research was supported by grant AGL2003-00640 from the Ministry of Education and Science (MEC), Spain. The authors thank Drs N. Vovlas and M. Di Vito for supplying Italian and Syrian populations of M. artiellia, and Drs B.B. Landa and J.A. Navas Cortés for reviewing the manuscript prior to submission.

\section{References}

Anwar, S.A., McKenry, M.V. \& FAddoul, J. (2000). Reproductive variability of field populations of Meloidogyne spp. on grape rootstocks. Journal of Nematology 32, 265-270.

Castillo, P., Mora-Rodriguez, Ma .P., NAvas-Cortés, J.A. \& JIMÉNEZ-DÍAZ, R.M. (1998). Interactions between Pratylenchus thornei and Fusarium oxysporum f. sp. ciceris on chickpea. Phytopathology 88, 836-844.

Castillo, P., Navas-Cortés, J.A., Gomar Tinoco, D., Di Vito, M. \& JimÉnEZ-DíAZ, R.M. (2003). Interactions between Meloidogyne artiellia, the cereal and legume rootknot nematode, and Fusarium oxysporum f. sp. ciceris race 5 in chickpea. Phytopathology 93, 1513-1523.

Di Vito, M. \& GRECO, N. (1988). Investigation on the biology of Meloidogyne artiellia. Revue de Nématologie 11, 223-227.

Di Vito, M. \& ZACCHEO, G. (1987). Response of cultivars of wheat to Meloidogyne artiellia. Nematologia Mediterranea 15, 405-408. 
Ferris, H., Schneider, S.M. \& Semenoff, M.C. (1984). Distributed egg production functions for Meloidogyne arenaria in grape varieties and consideration of the mechanistic relationship between plant and parasite. Journal of Nemato$\log y 16,178-183$.

GoMEZ, K.A. \& GoMEZ, A.A. (1984). Statistical procedures for agricultural research. 2nd Edition. New York, NY, USA, John Wiley \& Sons, 680 pp.

GReCO, N. (1984). Presenza di Meloidogyne artiellia su cece in Italia. Nematologia Mediterranea 12, 235-238.

Hussey, R.S. \& BARKER, K.R. (1973). A comparison of methods of collecting inocula of Meloidogyne spp., including a new technique. Plant Disease Reporter 57, 1025-1028.

Kyrou, N.C. (1969). First record of occurrence of Meloidogyne artiellia on wheat in Greece. Nematologica 15, 432-433.

PÉrez, M.P., NAVAs-Cortés, J.A., PAscual-VIllaLobos, M.J. \& CAstillo, P. (2003). Nematicidal activity of essential oils and organic amendments from Asteraceae against root-knot nematodes. Plant Pathology 52, 395-401.

Petrillo, M.D. \& Roberts, P.A. (1997). Variability of virulence among isofemale lines developed from two Meloido- gyne incognita isolates from the same field site. Journal of Nematology 29, 599-600.

RITTER, M. (1972). The economic importance of Meloidogyne in Europe and the Mediterranean Basin. OEPP/EPPO, Bulletin 6, 17-22.

Shaner, G., Stromberg, E.L., Lacy, G.H., Barker, K.R. \& PIRONE, T.P. (1992). Nomenclature and concepts of pathogenicity and virulence. Annual Review of Phytopathology 30, 47-66.

Tobar JimÉneZ, A. (1973). Nematodes de los secanos de la comarca de Alhama. I. Niveles de población y cultivos hospedadores. Revista Ibérica de Parasitología 33, 525-556.

Tzortzakakis, E.A., Trudgill, D.L. \& Phillips, M.S. (1998). Evidence for a dosage effect of the $M i$ gene on partially virulent isolates of Meloidogyne javanica. Journal of Nematology 30, 76-80.

Van Der Beek, J.G., Vereijken, P.F.G., PoleiJ, L.M. \& VAN SILFHOUT, C.H. (1997). Isolate-by-cultivar interaction in root-knot nematodes Meloidogyne hapla, M. chitwoodi, and M. fallax on potato. Canadian Journal of Botany 76, 7582. 